Volume 16(1) (2019), 1-14

Copyright @ 2020 Equinox Publishing Ltd

Sheffield

http://equinoxpub.com

https://doi.org/10.1558/cam.36271

\title{
Conflict in migrant doctor-local doctor communication in public healthcare institutions in Chile
}

\author{
MARIANA LAZZARO-SALAZAR ${ }^{1}$ AND LUCAS PUJOL-COLS ${ }^{2}$ \\ (1) Universidad Católica del Maule, Chile (2) National Scientific and Technical Research Council \\ (CONICET), Argentina
}

\begin{abstract}
When investigating intercultural communication in healthcare settings, interprofessional communication has received very little scholarly attention compared to doctor-patient interactions. Interactions among doctors, however, are an important locus for the organizational life of a hospital as the way these professionals communicate will promote (or hinder) professional effectiveness and efficiency. This paper presents the findings of a study that explores the perceptions concerning the degree and frequency of communicative conflict of 61 migrant doctors working in public healthcare institutions in the central region of El Maule in Chile. Drawing on data from a survey on communicative conflicts, the study analyses the perceptions of the migrant doctors in relation to one particular style of conflict management, namely, adaptability. Findings show that although communicative conflicts seem to occur only occasionally, moderate scores are reported for how such perceptions are believed to affect work performance. Also, the demands of communicative adaptability are perceived to be met largely by migrant doctors alone. The paper then offers considerations about the possible impact that these adaptability efforts could have on migrant doctors' integration processes.
\end{abstract}

Keywords: Chile; communicative conflict; conflict management; migrant doctors; intercultural communication; public healthcare settings

\section{Introduction}

Communication plays a central role in the adaptation and integration processes undergone by migrant doctors, since doctor-doctor communication helps to develop a sense of belonging, acceptance and integration within the new workplace. The extent to which migrant doctors are successful - in discussing medical matters as well as in engaging in personal conversations with colleagues in appropriate ways - has been shown to have a profound impact on the adaptation and integration processes, as language is the means of socialization through which migrant doctors adjust to their new roles, build professional relationships and, thus, become part of the new professional community (cf. Holmes et al. 2011: 83-106).

Conflict, on the other hand, is likely to arise if doctor-doctor communication is unsuccessful. As Brew and Cairns (2004: 332) explain, 'conflict is a natural part of the daily activities of any workplace', but they also warn us that 'when people from different cultural orientations are interacting, complications beyond the usual tensions may arise, due both to a differing array of needs and/or differing conflict negotiation styles'. In this light, it should be noted that regardless of whether they speak different languages (e.g. Lindhout et al. 2012) or the same language (e.g. Holmes and Marra 2002), interactants from different cultural backgrounds

\section{eøuınoxonlıne}


have different conceptualizations of what constitutes appropriate social behaviour, which often leads to cultural differences in the way people manage interactions (Ladegaard and Jenks 2015; see also Holmes 2012). This places communicative conflict at the core of interpersonal relations in migrant doctor-local doctor interactions.

As migrant doctors strive to integrate into a new workplace context, the management of communicative conflict may, naturally, result in feelings of stress and frustration, affecting their work performance, mental health and job satisfaction (Ding and Hargraves 2009). Communicative conflict may, thus, become a psychosocial risk factor, that is, a work-related factor which, either in excess, absence or combination, becomes a threat to the physical, social and/or psychological integrity of individuals (Meliá et al. 2006). To some extent, then, the appropriate negotiation of communicative conflicts, as a vital aspect of (inter) professional talk, can potentially result in poor or complete lack of adaptation and/or integration to the new workplace environment. Thus, the successful management of communicative conflict in migrant doctor-local doctor talk is important in mitigating and/or reducing the impact of this psychosocial risk factor and in maintaining harmonious social relations. With the aim of advancing our understanding of such workplace phenomena, this study explores migrant doctors' perceptions of communicative conflict in interactions with local doctors in public healthcare institutions in Chile and reflects on the impact this may have on migrant doctors' adaptation processes.

The following section provides a brief overview of research on interprofessional communication and the management of communicative conflict, and a description of intercultural healthcare institutions in Chile. Then the methodology employed in this study is outlined, which is followed by the presentation of the results of a self-reported survey that measures intercultural communicative conflict. The results show the migrant doctors' perceptions of the degree and frequency of communicative conflict they experience in public healthcare institutions in Chile. The discussion and conclusions focus on the ways in which adaptability, as one of the styles of conflict management, may influence the migrant doctors' integration processes.

\section{Literature review}

\section{1. (Inter)professional communication and the management of communicative conflict}

Communication among local and migrant doctors is certainly a core aspect of organizational life, as it may either enhance or hinder adaptation and integration processes. Intercultural communication research has shown that very often migrants find it hard to adapt to the new cultural norms of interaction and to engage in successful communication with people from other cultures, causing them anxiety and work distress (consider Glazer and Gyurak 2008). Distress occurs when perceived pressure to adapt to the new norms exceeds one's perceived ability to cope with the new workplace (Palmer et al. 2003). In this context of workplace reality, communication barriers, or miscommunication problems, and the mismatch of expectations of communication norms are likely to lead to acculturative stress, i.e. the type of stress that emerges directly as a result of the acculturation process (Hovey and Magaña 2000). This, in turn, will very likely lead to unsatisfactory workplace relationships and an unhealthy work environment (Kreitzer et al. 1997).

In particular, the management of communicative conflict is of salience in intercultural communication, as it is mediated by interactants' complex sociocultural and linguistic frameworks and conceptualizations of workplace practices (Gunnarsson 2013), which influence their choice of discursive resources (i.e. how they say things), and their preferred ways of displaying social participation. When interactants face communicative conflict they have an array of conflict management styles at their disposal, which ranges from competing (i.e. the pursuit of one's own concerns at the other person's expense), collaborating and compromising to accommodating (i.e. neglecting one's own concerns to satisfy those of the other person) and avoiding at the other end of the continuum (Sportsman and Hamilton 2007). Guided by their cultural assumptions, the preference for one style over others displays one's orientation to resolving, avoiding or actually creating and/or engaging in conflict. Thus, the appropriate management of the interactional resources embedded in this context of workplace interaction can strongly influence

\section{eevunoxonlıne}


how (dis)harmonious relationships are managed by doctors from different cultural backgrounds.

Interestingly, although the management of communicative conflict in the workplace has attracted considerable scholarly attention from researchers in organizational studies (e.g. De Dreu et al. 2001), intercultural communication (e.g. Posthuma et al. 2006), psychology (e.g. Alper et al. 2000), healthcare communication (e.g. Pilotto et al. 2007; Losa Iglesias and Becerro de Bengoa Vallejo 2012) and medical education (Hall et al. 2004; Skjeggestad et al. 2017) to name a few areas, to our knowledge there are no studies concerning this vital aspect of workplace interaction among doctors from different cultural backgrounds and, least of all, involving migrant doctors in Chile.

\subsection{Migrant doctors in Chile}

Healthcare organizations around the world are facing profound demographic shifts in their professional populations (consider, for example, a comparison between Chile and Hong Kong in Zayts and Lazzaro-Salazar 2020) and Chile is not an exception to this global trend. According to the Health Statistics of the Organization for Economic Co-operation and Development (henceforth, OECD), Chile has one of the lowest numbers of doctors per person among the OECD countries (1.9 doctors per 1,000 people in 2013, compared to 2.2 doctors in Mexico and, with the highest OECD average, 6.2 doctors in Greece - OECD 2014). This phenomenon naturally results in shortages of medical staff, which may account for the fact that migrant doctors in Chile constitute $17.9 \%$ of the country's medical workforce and $32 \%$ of medical personnel working in public health institutions (Leiva 2015), putting Chile in the fifth place among OECD countries with the highest percentages of migrant doctors. Naturally, as Chile continues to attract skilled migrants in the healthcare sector (see El Mercurio 2015), the rate of migrant doctors will continue to rise and social issues in this context will become more pressing.

In spite of this rapidly growing multicultural scenario, studies focusing on the Chilean context have, for the most part, exclusively explored the demographic characteristics of migrant domestic workers (Stefoni and Fernández 2011) and school children (Tijoux 2013), and only a few studies have investigated multicultural phenomena in healthcare settings in Chile. These studies, however, have only endeavoured to assess the implementation of socio-cultural programmes that aim to address cultural differences for the integration of the native people of Chile in the public healthcare system (e.g. Bolados 2009) and to study the cultural/communication needs of migrant patients in Chile (e.g. Urzúa et al. 2016). There are, however, no studies providing exploratory evidence of social phenomena in doctor-doctor communication or other kinds of professional practice in healthcare contexts in Chile. As a result, this paper explores communicative conflict among migrant doctors and their local counterparts, thus aiming to contribute to the under-researched field of doctordoctor communication (see Lazzaro-Salazar and Pujol-Cols 2017; Lazzaro-Salazar 2013) and to offer an opportunity to reflect on the importance of promoting cultural sensitivity in workplace settings to improve communication among health professionals.

\section{Data and methods}

A cross-sectional design was used and a self-report survey was administered to 61 migrant doctors working in public healthcare institutions in urban areas of the VII Region of El Maule in Chile between September and November 2016.

\subsection{Context}

According to a report issued by the Ministry of Health in April 2017, the El Maule region, located in the centre of Chile, has less than 12 doctors per 10,000 patients, making this one of the regions with the lowest densities of doctors in Chile's public healthcare institutions and the highest inequity levels of access to health professionals in the country. In interviews conducted with the managers of a number of public healthcare institutions and health organizations as part of the initial stages of the data collection process, it was found that the healthcare authorities in El Maule had actively recruited doctors from countries such as Argentina, Venezuela and Cuba in early 2010 as they were forced to address staff shortages amidst the chaotic sanitary situation resulting from the

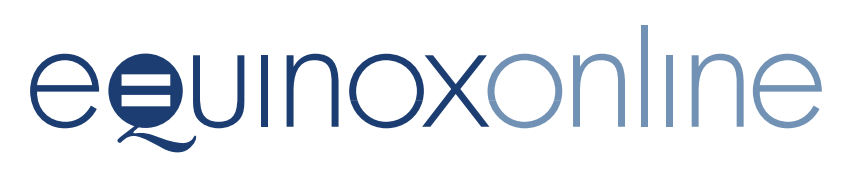


8.8 magnitude earthquake that hit the region in February of that year. Not surprisingly, then, there is an increasingly diverse population of medical practitioners currently found in El Maule's public hospitals.

\subsection{Participants}

At the time of the data collection (SeptemberNovember 2016), 72 migrant doctors were officially registered in the region to work in the public healthcare system. Given the fact that this was a reduced group of professional migrants and that public health offices and departments were unable to help us contact these doctors for legal reasons to do with privacy concerns, the difficulty in accessing these doctors made them a 'hidden population' (see Heckathorn 1997; Penrod et al. 2003). However, the authorities and other relevant staff of the public health institutions participating in this study were able to assist us by spreading word of our wish to make contact with migrant doctors, resulting in a 'snowball effect' for recruiting participants (Goodman 1961; Zayts and Lazzaro-Salazar 2020).

Table 1. Description of participants

\begin{tabular}{|l|l|r|}
\hline Category & & $\begin{array}{c}\text { Absolute } \\
\text { frequency }\end{array}$ \\
\hline Gender & Male & 26 \\
& Female & 35 \\
\hline Age & 30 years old or younger & 5 \\
& Between 31 and 35 & 15 \\
& Between 36 and 40 & 23 \\
& Between 41 and 45 & 10 \\
& Between 46 and 50 & 8 \\
\hline Country of & Venezuela & 43 \\
& Colombia & 7 \\
& Cuba & 3 \\
& Ecuador & 3 \\
& Argentina & 2 \\
& Dominican Republic & 2 \\
& Bolivia & 1 \\
\hline Medical & Paediatrician & 9 \\
specialty & Surgeon & 5 \\
& Anaesthesiologist & 12 \\
& General practitioner & 12 \\
& Gynaecologist & 4 \\
& Other & 24 \\
\hline
\end{tabular}

The migrant doctors were contacted one by one personally by the first author.

A total of 61 migrant doctors working in public healthcare institutions of the VII Region of El Maule in Chile participated in this study (see Table 1). Twenty-six of them are male and 35 are female. Most of the participants are between 36 and 40 years old and come from Venezuela. Finally, $61 \%$ of the participants are concentrated in four specialties, namely, paediatrics, surgery, anaesthesiology and general practice. These doctors have worked in Chile for an average of 2.67 years (standard deviation of 1.92 years), and most of them had decided to move to Chile for personal safety reasons $(70 \%)$, for economic advancement $(49.18 \%)$ and/or due to political unrest in their countries of origin (47.54\%). Also, it was found that $62.30 \%$ of the participants had over 10 years of experience in the medical profession.

\subsection{Instrument}

A survey on communicative conflict was designed by adapting the Dutch Test for Conflict Handling (DUTCH), which was validated in De Dreu et al. (2001) (also see Rahim 2001) and applied as part of a larger study on intercultural communication in public healthcare institutions in Chile. The survey has 47 items grouped in three core dimensions: (1) communicative conflict; (2) styles for managing communicative conflict, which include (a) adaptable, (b) dominant and (c) evasive; and (3) type of language used (direct/indirect language).

These three dimensions are present in two 5-point Likert scales, which constitute the two sections of the survey. In the first section, the survey has a scale that measures degrees of agreement to explore the perceived level of communicative conflict, use of styles for managing conflict and use of direct/indirect language among local and migrant doctors, with responses ranging from strongly disagree (1) to strongly agree (5). The second section has a scale of frequency that measures how often migrant doctors perceive communicative conflicts, use certain styles for managing conflict and direct/ indirect language with responses ranging from never (1) to very often (5). Of relevance for the topic explored in this article, the findings reported here correspond to the dimension of communicative conflict and one sub-dimension of styles

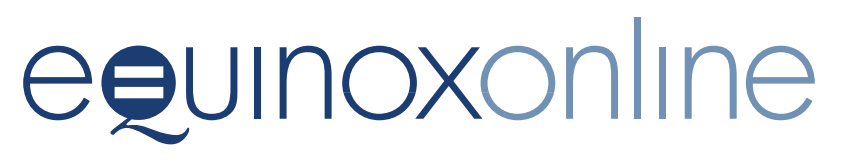


of conflict management, namely, an adaptable style.

\subsection{Data collection}

Following approval of the study from the Ethics Committee of Universidad Católica del Maule, Chile (records \#28/2015 and \#57/2017), participants were asked to fill in the survey on paper or electronically through an online link to a Google Drive $^{\mathrm{Tm}}$ form that was provided by email or Whatsapp ${ }^{\oplus}$ as requested by the doctors. The survey was preceded by a description of the study and a consent form. Access to the online survey was only granted if consent to participate in this study was given. Responses to the survey were anonymous. As noted above, the data for the study reported here was collected from September to November 2016. The original survey was in Spanish and it was also completed in Spanish.

\subsection{Analytical procedure}

The reliability of the three scales included in the communicational conflict survey (i.e. intensity of communicative conflict, frequency of communicative conflict and levels of adaptability) was examined in terms of their internal consistency by calculating Cronbach's alpha coefficients. Following Loewenthal (2001), values higher than .60 were considered to be indicators of satisfactory internal consistency. Descriptive statistics (means and standard deviations) and correlations were estimated for the three scales as well as for each of their respective items. Mean-difference tests were conducted to examine the influence of specific demographics (i.e., gender, age and years of residency in Chile) on reported levels of communicative conflict and adaptability. To this end, the participants were distinguished in various ways (i.e., male/female; 36 years old or older / younger than 36 years old; up to 24 months of residency / more than 24 months) and $t$ tests were then calculated. The potential influence of adaptability on perceived levels of frequency and intensity of communicative conflict was also analysed, again by separating the participants into two independent groups (i.e., adaptability levels above or below the mean) and conducting a $t$ test.

\section{Results}

Descriptive statistics and correlations among the intensity of communicative conflict, frequency of conflict and adaptability scales are reported in Table 2 (also see Figure 1). The results revealed that migrant doctors, on average, perceived moderate levels of intensity and frequency of communicative conflict at work, both variables being positively and moderately correlated in our sample. Furthermore, the levels of adaptability displayed positive, moderate and statistically significant correlations with both perceived intensity and frequency of conflict, which indicates that higher levels of intensity and frequency of communicative conflict are associated with increasing levels of adaptability. Finally, the results from

Table 2. Descriptive statistics, correlations and reliability per scale

\begin{tabular}{|l|c|c|c|c|c|c|c|c|c|}
\hline \multirow{2}{*}{ Scale } & \multirow{2}{*}{$\mathbf{M}$} & SD & \multirow{2}{*}{$\begin{array}{l}\text { Number } \\
\text { of items }\end{array}$} & & \multicolumn{3}{|c|}{ Levels } & \multicolumn{3}{c|}{ Correlations } \\
\cline { 5 - 10 } & & & & Low & Moderate & High & 1 & 2 & 3 \\
\hline $\begin{array}{l}\text { 1. Intensity of } \\
\text { communicative conflict }\end{array}$ & 2.23 & .92 & 5 & 34.43 & 49.18 & 16.39 & .80 & & \\
\hline $\begin{array}{l}\text { 2. Frequency of } \\
\text { communicative conflict }\end{array}$ & 1.96 & .79 & 5 & 42.62 & 50.82 & 6.56 & $.40^{* *}$ & .83 & \\
\hline 3. Degrees of adaptability & 3.14 & .63 & 8 & 1.64 & 52.46 & 45.9 & $.51^{* *}$ & $.26^{*}$ & .65 \\
\hline
\end{tabular}

Notes: $\mathrm{M}=$ Mean, $\mathrm{SD}=$ Standard deviation. ${ }^{* *} \mathrm{p}<.01,{ }^{*} \mathrm{p}<.05$. Reliability coefficients (Cronbach's alpha) are reported on the principal diagonal in italics. Levels of intensity and frequency of communicative conflict, and adaptability are expressed in perceptual terms. Levels of intensity and frequency of communicative conflict, and adaptability were calculated as follows: 1. Low = mean score lower than 1.67; 2 . Moderate = mean score higher or equal than 1.67 but lower than $3.33 ; 3$. High = mean score higher or equal than 3.33 .

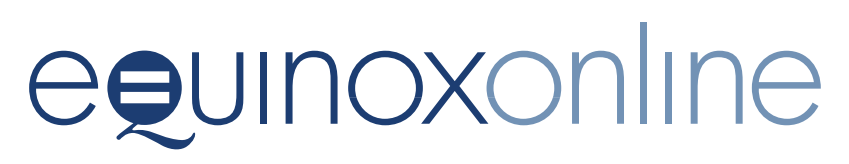


Figure 1. Levels of intensity of communicative conflict, frequency of communicative conflict and adaptability

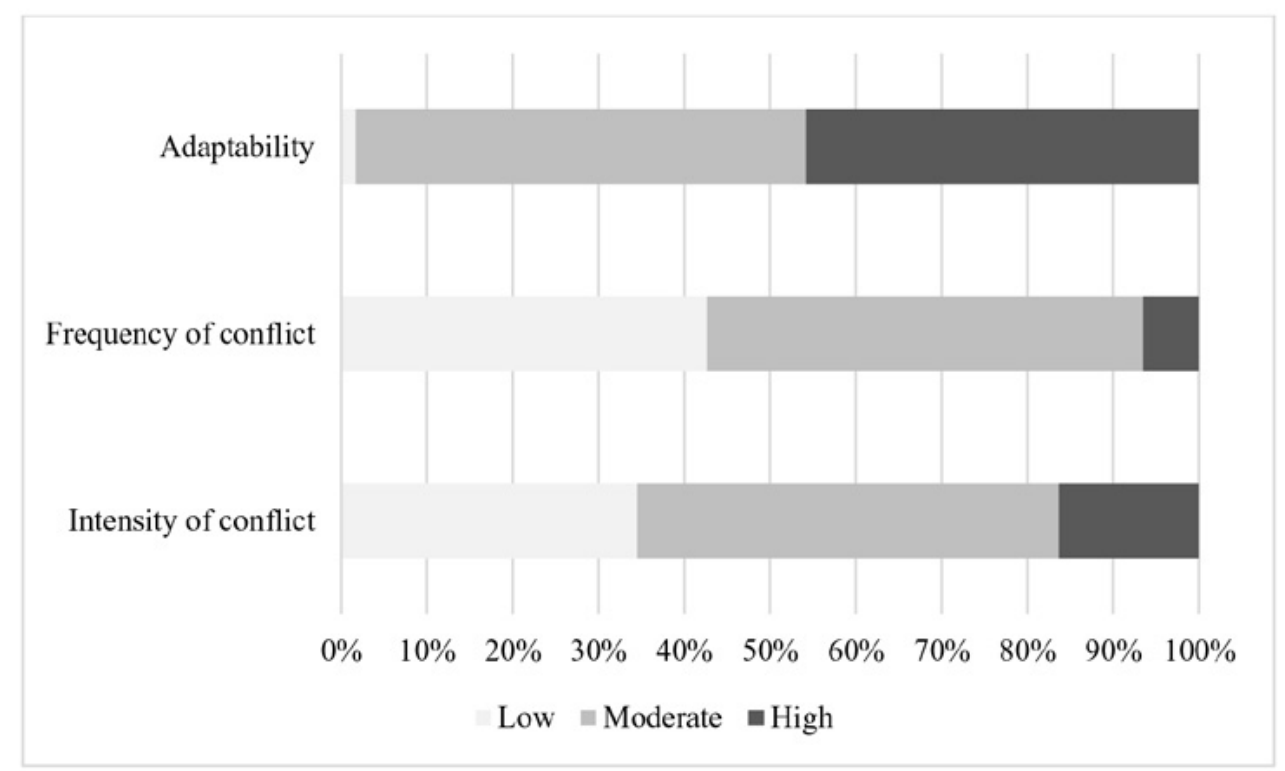

Note: Levels of intensity and frequency of communicative conflict and adaptability were calculated as follows: 1 . Low $=$ mean score lower than 1.67; . Moderate = mean score higher than or equal to 1.67 but lower than $3.33 ; 3$. High = mean score higher than or equal to 3.33 .

the $t$ tests revealed that adaptability significantly predicted both frequency and intensity of communicative conflict, indicating that perceived levels of frequency and intensity are higher for those participants who reported higher levels of adaptability (i.e., the level of adaptability is above the mean score), $t(59)=-2.40, p<.05, t(59)=-3.37$, $p<.01$.

With the aim of having a deeper understanding of the relationships among perceived intensity of communicative conflict, perceived frequency of communicative conflict and adaptability levels, descriptive statistics were also calculated for each of the three scales. Regarding the migrant doctors' perceived intensity of communicative conflict (see Table 3), scores range from 1.00 to 4.60 , with a mean of 2.23 and a standard deviation of .92 , suggesting moderate levels of intensity of communicative conflict. Furthermore, the results show that a significant majority of the participants (81.97\%) believe that regardless of the presence of communicative conflicts, they have been able to do their job adequately (item \#1). In addition, above a quarter of the participants (31.15\%) expressed that communicative conflicts led to confrontations with negative outcomes (item \#5), while lower results were obtained regarding the perceived impact of communicative conflict on the participants' anxiety (item \#4) and motivation levels (item \#3), and the quality of their relationships with their colleagues (item \#2). The results from the $t$ tests reveal no significant differences in the participants' perceptions of intensity of communicative conflict based on their gender, age or years of residency in Chile.

The results regarding the migrant doctors' perceived frequency of communicative conflicts are presented in Table 4 below. The scores range from 1.00 to 4.80 , with a mean of 1.96 and a standard deviation of .79, which suggests a low to moderate frequency of communicative conflict. The results from the $t$ tests reveal no significant differences in the participants' perceptions of frequency of communicative conflict based on their gender or age. Statistically significant differences were found, however, regarding the participants' years of residency in Chile, revealing that those participants who have lived in Chile for over two years tended to experience a higher frequency of communicative conflict, $t(59)=-3.29, p<.01$. In line with this, the results for item \#4 show that most participants $(77.05 \%)$ seem to believe that they never or rarely have communicative conflicts with their Chilean colleagues. However, when considering the results for item \#3, it can be noted that the perceived level of communicative conflict reported by the migrant




Table 3. Intensity of communicational conflicts

\begin{tabular}{|l|c|c|c|c|c|c|c|}
\hline Items & $\mathbf{M}$ & SD & $\begin{array}{c}\text { Strongly } \\
\text { disagree }\end{array}$ & Disagree & Neutral & $\begin{array}{c}\text { Agree } \\
\text { Strongly } \\
\text { agree }\end{array}$ \\
\hline $\begin{array}{l}\text { 1. Communication problems } \\
\text { prevent me from doing my job } \\
\text { satisfactorily. }\end{array}$ & 1.74 & 0.95 & 52.46 & 29.51 & 9.84 & 8.20 & 0 \\
\hline $\begin{array}{l}\text { 2. Communication problems } \\
\text { hinder the growth of positive } \\
\text { relationships with my } \\
\text { colleagues. }\end{array}$ & 2.28 & 1.25 & 37.70 & 22.95 & 16.39 & 19.67 & 3.28 \\
\hline $\begin{array}{l}\text { 3. Communicative conflicts } \\
\text { discourage me. }\end{array}$ & 2.25 & 1.32 & 37.70 & 31.15 & 8.20 & 14.75 & 8.20 \\
\hline $\begin{array}{l}\text { 4. Conflicts of communication } \\
\text { make me anxious. }\end{array}$ & 2.30 & 1.22 & 34.43 & 26.23 & 18.03 & 18.03 & 3.28 \\
\hline $\begin{array}{l}\text { 5. Communicative conflicts } \\
\text { end in confrontations that lead } \\
\text { nowhere. }\end{array}$ & 2.61 & 1.41 & 31.15 & 19.67 & 18.03 & 19.67 & 11.48 \\
\hline
\end{tabular}

Note: $\mathrm{M}=$ Mean, $\mathrm{SD}=$ Standard deviation. All values, except means and standard deviations, are expressed in perceptual terms.

doctors rises from $22.95 \%$ in item \#4 to over a third (37.69\%) in item \#3.

This inconsistency in the reported levels of communicative conflict could be due to the way both items are formulated. Indeed, in item \#3 the source of the problem is absent, and, thus, a positive response to it may not damage the professional image of self and others, which could have led the participants to report communicative conflict more freely. Item \#4, however, seems to be a double-edged sword since a positive response to this statement may not only make the Chilean doctors part of the conflict but also, in so doing, position the respondents as conflictive for 'having' such problems at work (see agentive use of verbs in Bruckmaier 2017; cf. 'face' in item \#3). A more

Table 4. Migrant doctors' perceived frequency of communicational conflicts

\begin{tabular}{|l|c|c|c|c|c|c|c|}
\hline Items & M & SD & Never & Rarely & Sometimes & Often & $\begin{array}{c}\text { Very } \\
\text { often }\end{array}$ \\
\hline $\begin{array}{l}\text { 1. My communication style has } \\
\text { prevented me from doing my job } \\
\text { properly. }\end{array}$ & 1.54 & 0.85 & 63.93 & 22.95 & 8.20 & 4.92 & 0 \\
\hline $\begin{array}{l}\text { 2. The communication style of my } \\
\text { Chilean colleagues has prevented } \\
\text { me from doing my job properly. }\end{array}$ & 1.87 & 1.09 & 49.18 & 27.87 & 13.11 & 6.56 & 3.28 \\
\hline $\begin{array}{l}\text { 3. I face communicational conflicts } \\
\text { at work. }\end{array}$ & 2.31 & 1.06 & 24.59 & 37.70 & 21.31 & 14.75 & 1.64 \\
\hline $\begin{array}{l}\text { 4. I have communication problems } \\
\text { with my Chilean colleagues. }\end{array}$ & 1.90 & 0.98 & 40.98 & 36.07 & 18.03 & 1.64 & 3.28 \\
\hline $\begin{array}{l}\text { 5. My Chilean colleagues make fun } \\
\text { of my communication style. }\end{array}$ & 2.16 & 1.11 & 36.07 & 26.23 & 26.23 & 8.20 & 3.28 \\
\hline
\end{tabular}

Note: $\mathrm{M}=$ Mean, $\mathrm{SD}$ = Standard deviation. All values, except means and standard deviations, are expressed in perceptual terms.

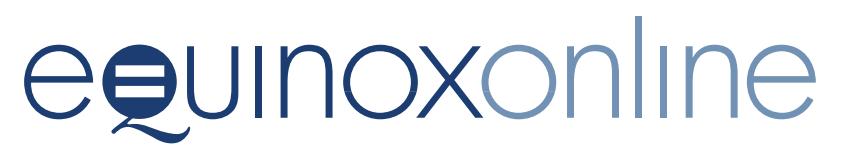


favourable response to item \#4 can then potentially damage the professional image of themselves and their colleagues (Kumar 1999). Another possible interpretation of the results for item \#3 is that the participants who reported moderate levels of communicative conflict in their workplaces perceive it with other co-workers rather than with their colleagues. This interpretation will be triangulated in future interviews with the participants, which is part of the methodological design of the wider study involving this data set.

Moreover, in spite of the moderate levels of communicative conflict reported, it should be noted that the majority of participants do not seem to perceive communicative conflict as an obstacle for doing their jobs. This refers to both self-oriented (item \#1) and other-oriented situations (item \#2). Also, while most participants report that their colleagues either never or rarely make fun of their way of communicating $(62.30 \%$, item \#5), there are still over $37 \%$ of the participants who report that their local counterparts make fun of their communication style either sometimes, often or very often.

The results regarding the sub-dimension adaptable within the styles for managing conflict dimension are presented in Table 5. The scores range from 1.50 to 4.13 , with a mean of 3.14 and a standard deviation of .63, suggesting moderate levels of communicative adaptability in the workplace as perceived by the migrant doctors. The results from the $t$ tests reveal no significant differences in the participants' perceived level of adaptability based on their gender, age or years of residency in Chile. The scores for item \#7 show that $52.46 \%$ of the migrant doctors would rather adapt to the local norms of communication, while the scores for item \#2 show that $70.49 \%$ of the migrant doctors believe they have already changed the way they communicate to adapt to that of their Chilean colleagues.

Table 5. Style of conflict management: Adaptable

\begin{tabular}{|c|c|c|c|c|c|c|c|}
\hline Items & $\mathbf{M}$ & SD & $\begin{array}{l}\text { Strongly } \\
\text { disagree }\end{array}$ & Disagree & Neutral & Agree & $\begin{array}{l}\text { Strongly } \\
\text { agree }\end{array}$ \\
\hline $\begin{array}{l}\text { 1. I should change my } \\
\text { communication style to that of } \\
\text { my Chilean colleagues. }\end{array}$ & 2.25 & 1.15 & 31.15 & 34.43 & 16.39 & 14.75 & 3.28 \\
\hline $\begin{array}{l}\text { 2. I had to adapt the way I talk } \\
\text { when I started working in Chile. }\end{array}$ & 3.70 & 1.26 & 8.20 & 13.11 & 8.20 & 40.98 & 29.51 \\
\hline $\begin{array}{l}\text { 3. I feel that the other } \\
\text { professionals with whom I } \\
\text { work have adapted their way of } \\
\text { communicating to mine. }\end{array}$ & 2.30 & 1.22 & 34.43 & 26.23 & 18.03 & 18.03 & 3.28 \\
\hline $\begin{array}{l}\text { 4. Communication with } \\
\text { my Chilean colleagues has } \\
\text { improved over time. }\end{array}$ & 3.89 & 1.11 & 4.92 & 8.20 & 13.11 & 40.98 & 32.79 \\
\hline $\begin{array}{l}\text { 5. I'd rather find another time } \\
\text { to clarify misunderstandings. }\end{array}$ & 2.66 & 1.22 & 21.31 & 27.87 & 19.67 & 26.23 & 4.92 \\
\hline $\begin{array}{l}\text { 6. I prefer to look for different } \\
\text { ways of communicating what I } \\
\text { mean. }\end{array}$ & 3.59 & .99 & 3.28 & 11.48 & 22.95 & 47.54 & 14.75 \\
\hline $\begin{array}{l}\text { 7. I prefer to adapt to the other } \\
\text { person's way of communicating. }\end{array}$ & 3.31 & 1.09 & 9.84 & 9.84 & 27.87 & 44.26 & 8.20 \\
\hline $\begin{array}{l}\text { 8. I have to change my } \\
\text { communication style to that of } \\
\text { my Chilean colleagues. }\end{array}$ & 3.39 & 1.26 & 9.84 & 14.75 & 22.95 & 31.15 & 21.31 \\
\hline
\end{tabular}

Note: $\mathrm{M}=$ Mean, $\mathrm{SD}$ = Standard deviation. All values, except means and standard deviations, are expressed in perceptual terms.

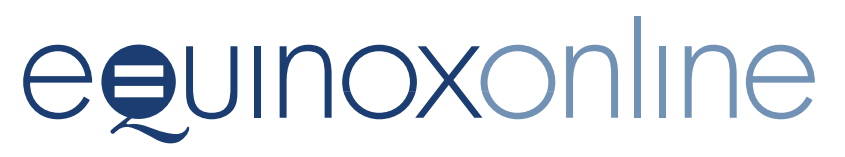


Here, it should be mentioned that some migrant doctors (21.31\%) also acknowledged that their local counterparts make an effort to adjust to their communication style (item \#3). Moreover, most participants $(62.29 \%)$ reported that they usually try to find other ways to express what they mean in case of misunderstandings (item \#6). In this light, the results for item \#5 suggest that nearly half of the migrant doctors (49.18\%) seem to have a preference for using a problem-solving, adaptable strategy when anticipating or faced with communicative conflicts. Possibly, as a consequence of these adjustments and beliefs reported for the items just discussed, the results obtained for item \#4 show that the migrant doctors (73.77\%) believe that the communication between them and their local counterparts has improved over time.

Interestingly, it should be noted that in spite of these positive attitudes and beliefs about migrant doctor-local doctor communication, $65.58 \%$ of the participants expressed that they believe they should not change their way of communicating to that of their Chilean colleagues (item \#1). This is clearly in tension with the responses reported for item \#8, as $52.46 \%$ of the participants express that they believe they have to change their communicative style to that of their Chilean counterparts. These results seem to suggest that the pressure to adapt to local norms of communication is imposed on them, an obligation that is conveyed through the verb have to (item \#8). In this way, these migrant doctors may adopt this adaptable attitude at the expense of what they believe they should do, possibly in order to orient to maintaining positive relationships with their local colleagues.

\section{Discussion and conclusions}

This study explored a group of migrant doctors' perceptions of communicative conflict and their efforts to adapt when communicating with their local counterparts in public healthcare institutions in Chile. The study shows that, when considering the participants' perceptions of the frequency and intensity of communicative conflicts between them and their local colleagues, the results are encouraging, as communicative conflicts do not seem to overwhelmingly characterize the daily professional routines of the migrant doctors or the relationships among colleagues. Such conflicts have been mostly reported to occur with low frequencies, and possibly not always involving the Chilean colleagues alone. Very importantly, most participants believe that the communicative conflicts they face in their workplaces do not affect their work performance, which could be regarded as consistent with their perception that communicative conflicts do not seem to discourage them or make them anxious. Moreover, the results also show that almost half of the participants have a negative attitude towards engaging in conflict, as they believe that conflict does not lead to positive outcomes.

This negative attitude towards engaging in conflict is also reflected in the results obtained for communicative adaptability. The moderate levels of communicative adaptability reported in this study show that these migrant doctors have a clear orientation towards adopting a problem-solving attitude when dealing with communicative conflicts. In this light, most migrant doctors participating in this study display a preference for finding another moment to clarify misunderstandings and different ways of explaining what they mean when they are not understood. This displays a preference for communication strategies that maintain positive self and other professional images and orient towards constructing harmonious relationships.

At this stage, however, two points should be emphasized in regard to what the participants reported in terms of adaptation processes. First, as noted above, the migrant doctors seem to experience a clear tension between how they believe they should behave in the event of communicative conflicts (i.e. whether they believe they should/ have to adapt to the local norms) and what they would rather do in actual practice. The results suggest that although the migrant doctors believe they should not change how they communicate, they prefer to adopt an adaptable style of conflict management, possibly in order to avoid conflict and thus build positive relationships with colleagues so as to integrate into the new workplace. The second point to be mentioned follows from the above as it refers to what the migrant doctors actually do in practice, that is to say, whether they perceive they actually adapt the way they talk and whether they feel their Chilean counterparts make the same communicative effort. In this regard, the migrant doctors in this study believe the burden

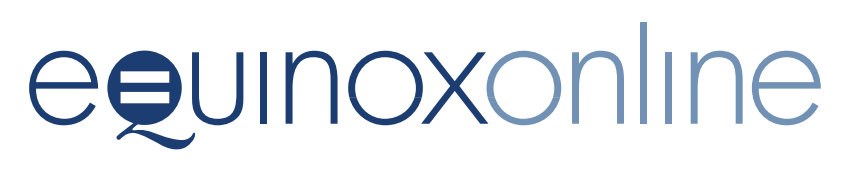


is not equally shared as their counterparts do not seem to try as hard to negotiate communication differences. Thus, as the migrant doctors seem to move along a continuum of beliefs that resist the change of communication style and the awareness that they need to adapt to integrate, the adaptation process may, to some degree, become a burden.

As Kim (2001: 54) explains, in the process of adaptation to a new culture, it is the 'strangers' (i.e. the migrants) that 'bear the burden of making the adjustments themselves almost exclusively'. Thus, as the migrant doctors in the present study struggle to retain some of their own cultural identity through their communication style, they also face the need to adapt it to fit in. Kim (2001: 55) summarizes this phenomenon as 'the need for acculturation and the resistance to deculturation, which 'inevitably causes stress in the strangers' psyche.' In this regard, Moncada et al. (2004) claim that the psychological demands to hide emotions and, we may add, beliefs become a psychosocial risk factor that not only requires additional cognitive efforts but also the management of any negative emotions that may be experienced as a result of this process.

This consideration of the demands to adapt imposed on the migrant doctors by this new context brings us back to our first consideration in this section: even if a majority of the participants do not perceive communicative conflicts to occur frequently or to play an important role in their communication with colleagues (in Table 3, 62.29\% for item \#3 and $77.05 \%$ for item \#4), we cannot turn a blind eye on the significant minorities $(37.71 \%$ and 22.95\%) who do report communicative conflicts to occur with a frequency from sometimes to often. It is also worth noting that Table 2 above in relation to items \#1 and \#5 shows respectively $18.04 \%$ and $31.15 \%$ of the participants think that communicative conflicts hinder professional practice, as the results show that a moderate number of participants are more vulnerable to having to make communicative adjustments.

The demands of having to handle communicative conflict in the workplace by adapting communication styles, combined with insufficient organizational resources, are likely to lead to feelings of distress which, if sustained over time, may have a detrimental effect on the physical and mental health of the migrant doctors. This is not always the case, as individuals may perceive the experience of stress in different ways or to different extents (Craddock and Folse 2016), but it is the case that communicative conflict, and communicative adaptability as a way of managing such conflict, can be problematic in intercultural professional settings, with a negative impact on social relations and the work environment. This naturally raises the need to conduct further workplace research to address such issues as, for instance, the levels and kinds of stress displayed by migrant doctors. Moreover, much is to be gained from employing other methods of data collection such as focus groups and the recording of naturally occurring situations that can complement those employed in this study to provide further insights into the issues of inter-professional communication and adaptation processes of migrant doctors.

Here we would like to emphasize that adaptation processes in the context of intercultural workplaces is a two-way street. This means that the burden of reducing communication barriers and adapting communication styles should be shared by migrants and locals equally. To achieve this, it is highly necessary to promote the development of cultural sensitivity (CS) so that making fun of somebody's communication style, for instance, ceases to be appropriate behaviour. Rooted in the values of understanding and respecting other people's norms, beliefs and attitudes, CS is defined as a willingness to use cultural knowledge while interacting with people from other cultures (Ulrey and Amason 2001) (also see culturally competent healthcare systems in Anderson et al. 2003).

Although the concept of CS in medicine has originally been developed with the goal of improving the doctor-patient relationship, the principles behind it can also be applied to interprofessional intercultural communication. According to Altshuler et al. (2003: 387), an 'awareness of cultural differences and the ability to respond to them appropriately' is key for achieving organizational integration. Thus, the need to provide migrant doctors with social tools that help them get acquainted with relevant aspects of the Chilean culture such as ways of communicating and the need to educate Chilean doctors to embrace cultural diversity should both be in Chile's agenda of social development.

Moreover, the role of leaders in providing additional organizational resources to cope

\section{eevinoxonlıne}


with stressors becomes crucial in such complex intercultural contexts. This is even more relevant during the first stages of the adaptation process, in which migrants face the double challenge of adjusting to both the cultural norms and values of a new country, and the idiosyncrasy of a new work context. From the point of view of organizational management, providing organizational resources, such as social support and training of both local and migrant doctors regarding communication norms and cultural expectations of doctor-doctor interaction are essential for the successful integration of migrants (Salgado et al. 2012). It is important to emphasise that even when migrants and locals speak the same language (as in this case), their understanding of what constitutes appropriate social behaviour may differ according to their cultural backgrounds, which is why raising awareness of these differences can help improve communication and doctor-doctor relations.

The cultural diversity that characterizes today's healthcare institutions presents researchers and management teams with the challenge of exploring interpersonal phenomena at the core of these workplaces. We believe that obtaining the kind of information presented in this study is vital for designing socially responsible personnel management strategies that succeed in enhancing the effectiveness of multicultural teams and in protecting the mental health of their members as well as in fostering healthy work environments by lessening the impact of psychosocial risk factors related to adaptation and integration processes. Moreover, an understanding of intercultural phenomena in healthcare institutions can help develop future evidence-informed strategies and policies, both aimed at promoting the social integration of migrant doctors and at recruiting and retaining these professionals.

\section{Note}

1. This is according to official data obtained through a citizen consultation request made via the website of the Health Services Office of the El Maule region.

\section{Acknowledgments}

This research was supported by the National Scientific and Technical Research Council (CONICET, Comisión Nacional de Investigación Científica y Tecnológica) FONDECYT n ${ }^{\circ} 3160104$, 'Communication and interculturality in public healthcare institutions in Chile'. We would like to thank the migrant doctors who participated in this study, our families for supporting us throughout the research process and especially Enrique Mundaca for his patience and advice.

\section{References}

Alper, Steve, Dean Tjosvold and Kenneth Law (2000) Conflict management, efficacy, and performance in organizational teams. Personnel Psychology 53 (3): 625-642. https://doi.org/ 10.1111/j.1744-6570.2000.tb00216.x

Altshuler, Lisa, Nan Sussman and Elizabeth Kachur (2003) Assessing changes in intercultural sensitivity among physician trainees using the intercultural development inventory. International Journal of Intercultural Relations 27 (4): 387-401. https:// doi.org/10.1016/S0147-1767(03)00029-4

Anderson, Laurie, Susan Scrimshaw, Mindy Fullilove, Jonathan Fielding and Jacques Normand (2003) Culturally competent healthcare systems: A systematic review. American Journal of Preventive Medicine 24 (3): 68-79. https://doi.org/10.1016/ S0749-3797(02)00657-8

Bolados, Paola (2009) ¿Participación o pacificación social? La lógica neoliberal en el campo de la salud intercultural en Chile: El caso Atacameño. Estudios Atacameños 38: 93-106. https://doi. org/10.4067/S0718-10432009000200007

Brew, Frances and David Cairns (2004) Do culture or situational constraints determine choice of direct or indirect styles in intercultural workplace conflicts? International Journal of Intercultural Relations 28 (5): 331-352. https:// doi.org/10.1016/j.ijintrel.2004.09.001

Bruckmaier, Elisabeth (2017) Getting at GET in World Englishes: A Corpus-Based Semasiological-Syntactic Analysis. Topics in English Linguistics 95. Berlin: Walter de Gruyter. https://doi.org/10.1515/9783110497311

\section{eevunoxonlıne}


Craddock, Christopher and Kimberly Folse (2016) Psychological stress of Hispanics living on the border. Journal of Immigrant and Minority Health 18 (4): 856-863. https://doi.org/10.1007/ s10903-015-0295-9

De Dreu, Carsten, Arne Evers, Biana Beersma, Esther Kluwer and Aukje Nauta (2001) A theory-based measure of conflict management strategies in the workplace. Journal of Organizational Behavior 22 (6): 645-668. https://doi.org/10.1002/job.107

Ding, Hongliu and Lee Hargraves (2009) Stressassociated poor health among adult immigrants with a language barrier in the United States. Journal of Immigrant and Minority Health 11 (6): 446-452. https://doi.org/10.1007/s10903008-9200-0

El Mercurio (2015) Chile frente a sus inmigrantes. El Mercurio Blogs 14 March. Available online http:// www.elmercurio.com/blogs/2015/03/14/30146/ Chile-frente-a-sus-inmigrantes.aspx

Glazer, Sharon and Anett Gyurak (2008) Sources of occupational stress among nurses in five countries. International Journal of Intercultural Relations 32 (1): 49-66. https://doi.org/10.1016/j. ijintrel.2007.10.003

Goodman, Leo (1961) Snowball sampling. Annals of Mathematical Statistics 32 (1): 148-170. https:// doi.org/10.1214/aoms/1177705148

Gunnarsson, Britt-Louise (2013) Multilingualism in the workplace. Annual Review of Applied Linguistics 33: 162-189. https://doi.org/10.1017/ $\underline{\text { S0267190513000123 }}$

Hall, Pippa, Erin Keely, Suzan Dojeiji, Anna Byszewski and Meridith Marks (2004) Communication skills, cultural challenges and individual support: Challenges of international medical graduates in a Canadian healthcare environment. Medical Teacher 26 (2): 120-125. https://doi.org/10.1080/ 01421590310001653982

Heckathorn, Douglas (1997) Respondent-driven sampling: A new approach to the study of hidden populations. Social Problems 44 (2): 174-199. https://doi.org/10.2307/3096941

Holmes, Janet (2012) Politeness in intercultural discourse and communication. In Christina Paulston, Scott Kiesling and Elizabeth Rangel (eds) The Handbook of Intercultural Discourse and Communication, 205-228. Oxford: WileyBlackwell. https://doi.org/10.1002/978111824 7273.ch11

Holmes, Janet and Meredith Marra (2002) Having a laugh at work: How humour contributes to workplace culture. Journal of Pragmatics 34 (12): 1683-1710. https://doi.org/10.1016/ S0378-2166(02)00032-2

Holmes, Janet, Meredith Marra and Bernadette Vine (2011) Leadership, Discourse, and Ethnicity. Oxford: Oxford University Press. https://doi. org/10.1093/acprof:oso/9780199730759.001.0001

Hovey, Joseph and Cristina Magaña (2000) Acculturative stress, anxiety, and depression among Mexican immigrant farmworkers in the Midwest United States. Journal of Immigrant Health 2 (3): 119-131. https://doi.org/10.1023/ A:1009556802759

Kim, Young (2001) Becoming Intercultural: An Integrative Theory of Communication and Cross-Cultural Adaptation. London: Sage.

Kreitzer, Mary, Donna Wright, Carol Hamlin, Sue Towey, Margo Marko and Joanne Disch (1997) Creating a healthy work environment in the midst of organizational change and transition. Journal of Nursing Administration 27 (6): 35-41. https://doi. org/10.1097/00005110-199706000-00011

Kumar, Rajesh (1999) Communicative conflict in intercultural negotiations: The case of American and Japanese business negotiations. International Negotiation 4 (1): 63-78. https://doi.org/ $\underline{10.1163 / 15718069920848372}$

Ladegaard, Hans and Christopher Jenks (2015) Language and intercultural communication in the workplace: Critical approaches to theory and practice. Language and Intercultural Communication 15 (1): 1-12. https://doi.org/10.1080/ $\underline{14708477.2014 .985302}$

Lazzaro-Salazar, Mariana (2013) Investigating Nurses' Professional Identity Construction in Two Health Settings in New Zealand. Unpublished doctoral dissertation, Victoria University of Wellington, New Zealand.

Lazzaro-Salazar, Mariana and Lucas Pujol-Cols (2017) Riesgos psicosociales e integración profesional de médicos extranjeros: Un estudio sobre el manejo del conflicto en la zona central de Chile. Revista Médica de Chile 145 (10): 1300-1307. https://doi. org/10.4067/S0034-98872017001001300

Leiva, Lorena (2015) El papel de los médicos extranjeros en consultorios. La Tercera, 12 October. Available online: http://www2.latercera. com/noticia/el-papel-de-los-medicos-extran jeros-en-consultorios/

Lindhout, Paul, Paul Swuste, Truus Teunissen and Ben Ale (2012) Safety in multilingual work settings: Reviewing a neglected subject in

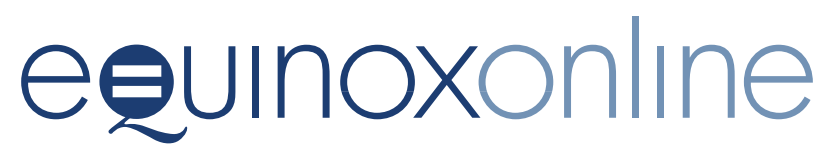


European Union policymaking. European Journal of Language Policy 4 (2): 137-170. https://doi. org/10.3828/ejlp.2012.10

Loewenthal, K. 2001. An Introduction to Psychological Tests and Scales (2nd edition). Hove, UK: Psychology Press.

Losa Iglesias, Marta and Ricardo Becerro de Bengoa Vallejo (2012) Conflict resolution styles in the nursing profession. Contemporary Nurse 43 (1): 73-80. https://doi.org/10.5172/conu.2012.43.1.73

Meliá, José, Clotilde Nogareda, Matilde Lahera, Antonio Duro, José Peiró, Marisa Salanova and Diego Gracia (2006) Principios Comunes para la Evaluación de los Riesgos Psicosociales en la Empresa. In José Meliá, Clotilde Nogareda, Matilde Lahera, Antonio Duro, José Peiró, Marisa Salanova, Diego Gracia et al. (eds) Perspectivas de Intervención en Riesgos Psicosociales. Evaluación de Riesgos, 13-36. Barcelona: Foment del Treball Nacional.

Ministry of Health (2017) Informe Sobre Brechas de Personal de Salud por Servicio de Salud: Glosa 01, letra i. Ley de Presupuestos Año 2017. Available online: http://web.minsal.cl/wp-content/uploads/ 2015/08/Informe-Brechas-RHS-en-Sector-P\%C3 \%BAblico_Abril2017.pdf

Moncada, Salvador, Clara Llorens and Tage Kristensen (2004). Manual para la Evaluación de Riesgos Psicosociales en el Trabajo. CoPsoQ ISTAS 21. Barcelona: Instituto Sindical de Trabajo, Ambiente y Salud.

OECD (2014) OECD Health Statistics 2014 Frequently requested data. Available online: http://www.oecd.org/els/health-systems/oecdhealth-statistics-2014-frequently-requested-data. htm

Palmer, Benjamin, Lisa Gardner and Con Stough (2003) The relationship between emotional intelligence, personality and effective leadership. Paper presented at the Fifth Australian Industrial and Organizational Psychology Conference.

Penrod, Janice, Deborah Preston, Richard Cain and Michael Starks (2003) A discussion of chain referral as a method of sampling hard-to-reach populations. Journal of Transcultural Nursing 14 (2): 100-107. https://doi.org/10.1177/1043659602250614

Pilotto, Louise, Geraldine Duncan and Jane Anderson-Wurf(2007) Issues for clinicians training international medical graduates: A systematic review. Medical Journal of Australia 187 (4): 225228. https://doi.org/10.5694/j.1326-5377.2007. tb01204.x
Posthuma, Richard, George White III, James Dworkin, Oscar Yánez and Stella Swift (2006) Conflict resolution styles between co-workers in US and Mexican cultures. International Journal of Conflict Management 17 (3): 242-260. https:// doi.org/10.1108/10444060610742344

Rahim, M. Afzalur (2001) Managing Conflict in Organizations (3rd edition). Westport, CT: Quorum Books.

Salgado, Hugo, Sheila Castañeda, Gregory Talavera and Suzanne Lindsay (2012) The role of social support and acculturative stress in health-related quality of life among day laborers in Northern San Diego. Journal of Immigrant and Minority Health 14 (3): 379-385. https://doi.org/10.1007/ s10903-011-9568-0

Skjeggestad, Erik, Jennifer Gerwing and Pål Gulbrandsen (2017) Language barriers and professional identity: A qualitative interview study of newly employed international medical doctors and Norwegian colleagues. Patient Education and Counseling 100 (8): 1466-1472. https://doi. org/10.1016/j.pec.2017.03.007

Sportsman, Susan and Patti Hamilton (2007) Conflict management styles in the health professions. Journal of Professional Nursing 23 (3): 157-166. https://doi.org/10.1016/j.profnurs.2007.01.010

Stefoni, Carolina and Rosario Fernández (2011) Mujeres inmigrantes en el trabajo doméstico: Entre el servilismo y los derechos. In Carolina Stefoni (ed.) Mujeres Inmigrantes en Chile: ¿Mano de Obra Ttrabajadoras con Derechos? Santiago de Chile: Ediciones Universidad Alberto Hurtado.

Tijoux, María (2013) Las escuelas de la inmigración en la ciudad de Santiago: Elementos para una educación contra el racismo. Polis. Revista Latinoamericana 12 (35): 287-307. https://doi. org/10.4067/S0718-65682013000200013

Ulrey, Kelsy and Patricia Amason (2001) Intercultural communication between patients and health care providers: An exploration of intercultural communication effectiveness, cultural sensitivity, stress, and anxiety. Journal of Health Communication 13 (4): 449-463. https://doi.org/10. 1207/S15327027HC1304_06

Urzúa, Alfonso, Osvaldo Heredia and Alejandra Caqueo-Urizar (2016) Mental health and stress by acculturation in immigrants from South America in northern Chile. Revista Médica de Chile 144 (5): 563-570. https://doi.org/10.4067/ S0034-98872016000500002

\section{eevunoxonlıne}




\section{4

Zayts, Olga and Mariana Lazzaro-Salazar (2020) Healthcare communication in multicultural contexts: Exploring professional mobility. In Zsófia Demjén (ed.) Applying Linguistics in Illness and Healthcare Contexts, 299-325. London: Bloomsbury.

Mariana Lazzaro-Salazar is a research associate in the Language in the Workplace Project, Victoria University of Wellington, New Zealand. She is an associate lecturer at the Centro de Investigación de Estudios Avanzados, the vice-president of the Ethics Committee and a member of the $\mathrm{PhD}$ programmes of Education and of Psychology at Universidad Católica del Maule, Chile. Her research has focused on healthcare communication, including nurses' construction of professional identity and the co-construction of narratives in the doctor-patient interview. Her current research project focuses on intercultural communication among physicians in the public healthcare system of Chile. Address for correspondence: Universidad Católica del Maule, Vicerrectoría de Investigación y Postgrado, Carmen 684, 3340000 Curicó, Chile. Email: lazzaromari@ gmail.com / mlazzaro@ucm.cl

Lucas Pujol-Cols received his PhD in Management and Organizational Behaviour from UNICEN (Argentina). He is a research associate at Universidad Católica del Maule (Chile), a research fellow at the National Scientific and Technical Research Council (Consejo Nacional de Investigaciones Científicas y Técnicas, Argentina) and a lecturer of Organizational Behaviour at Universidad Nacional de Mar del Plata (Argentina). His research interests include employee-employer relationships in the context of knowledge-based organizations and the mechanisms that underlie the effects of working conditions and personality traits on employees' attitudes, intentions, behaviours and wellbeing. Address for correspondence: Funes 3250, Mar del Plata 7600, Argentina. Email: lucaspujolcols@gmail.com 